\title{
Elimination of unplanned treatment breaks and dose reductions caused by mucositis: Positive implications for survival outcomes and cost reductions using high potency polymerized cross-linked sucralfate in $\mathbf{5 5}$ patients undergoing radiation for head and neck cancer with and without chemotherapy
}

\author{
Ricky Wayne McCullough ${ }^{1,2}$ \\ ${ }^{1}$ Translational Medicine Clinic and Research Center, Storrs, CT; \\ ${ }^{2}$ Department of Medicine and Emergency Medicine Veterans Administration Medical Center, Teaching Hospital, Warren Alpert Medical School of \\ Brown University, Providence, RI, USA
}

Purpose: Annually 27,855 patients in Korea develop treatment-induced mucositis nearly doubling the cost of cancer care. It is an emergency medical condition causing unplanned treatment breaks in 4,998 patients. The subsequent reduction in optimal dose-intensity causes premature deaths due to lower 5-year survival. An additional 216 patients die from mucositis-mediated sepsis and infection. Thus complete elimination of mucositis will immediately reduce the cost of care while simultaneously eliminating 5,214 mucositis-associated deaths. High potency polymerized cross-linked sucralfate (HPPCLS) cleared by the US Food and Drug Administration has been associated with the elimination of mucositis.

Methods: Observational, self-reporting, practice-based mucositis registry. Inclusion criteria: any patient with chemoradiation-induced mucositis. Exclusion criteria: previous adverse reaction to sucralfate products. Primary outcome: rapid reversal or complete prevention. Conduct of study: 28 radiation oncologists from 21 different institutions prescribed HPPCLS to 55 patients undergoing chemoradiation for squamous cell carcinoma of head and neck and esophagus to eliminate mucositis-associated treatment breaks.

Results: All patients with World Health Organization grade $1(n=6)$, grade $2(n=23)$, grade $3(n=16)$ oral mucositis, and grade 2 esophageal mucositis $(n=2)$ experienced complete reversal of mucositis. Within 2-3 days both mucosa and swallowing normalized. Anticipated grade $3 / 4$ mucositis was prevented in 8 out of 8 elderly patients aged 78-93 avoiding gastrostomy tube placement. Statistical analysis of outcomes: Outcomes qualified as a positive Glasziou treatment effect that was statistically significant $(P<0.05)$.

Conclusion: HPPCLS eliminated mucositis by rapid reversal or complete prevention, thereby eliminating unplanned treatment breaks. It may likely reduce mucositis-associated increased cost of care and premature deaths.

Keywords: Polymerized-Sucralfate, ProThelial, Mucositis, Unplanned-treatment-breaks, High potency polymerized cross-linked sucralfate

Received: Aug 29, 2016 Accepted: Dec 16, 2016

Correspondence to: Ricky Wayne McCullough

Translational Medicine Clinic and Research Center, 1768 Storrs Road,

Storrs, CT 08268, USA

Tel: +1-860-477-0961 Fax: +1-860-477-0962

E-mail: rwmmd@muellermedical.com

Copyright $@$ Korean Society of Surgical Oncology

This is an Open Access article distributed under the terms of the Creative Commons Attribution Non-Commercial License (http://creativecommons.org/licenses/by-nc/4.0) which permits unrestricted non-commercial use, distribution, and reproduction in any medium, provided the original work is properly cited.

\section{INTRODUCTION}

Chemoradiation induced mucositis is an emergency medical condition [1]. Due to the lack of meaningful therapeutic agents mucositis has become an accepted complication of cancer treatment to be tolerated, rather than a toxicity to be eliminated. Ineffective therapeutic options over the past several decades have forced acceptance of increased costs and unavoidable morbidity. Mucositis causes serious dysfunction in cancer treatment patients, disrupting their ability to swallow, to painlessly self-feed and to attend to self- 
care [1]. This condition contributes directly to reduced survival in patients who die annually from mucositis-mediated infections [2]. Additionally, mucositis patients forced by the disease to delay, reduce or discontinue chemoradiation reduce required dose-intensity of treatment and thereby experience premature cancer deaths due to early recurrence of neoplastic disease [3,4]. Complete prevention or rapid elimination of mucositis would eliminate all mucositis-associated cancer deaths as well as the increased cost of care required for these patients.

The experience of chemoradiation induced mucositis in Korean has been well-reported [5-7]. In 2012, there were 224,177 patients diagnosed with cancer. Oncology practice guidelines of National Cancer Center Network (NCCN) used in Korea [8], commits 22\% of these patients, or 49,319, to chemotherapy (CT) [9]. Besides those requiring chemotherapy, there are 8,543 patients with head and neck cancer (HNC) involving the lip, oral cavity, pharynx, larynx, esophagus and thyroid (anaplastic thyroid cancer) that require radiation for cure [10]. Given that, on average annually, $0.8 \%$ of all Korean cancer patients $[11,12]$ undergo human stem cell transplantation (HSCT) there is an additional 1,961 cancer patients. Overall, treatment-induced mucositis has been documented to occur in $37 \%$ of patients receiving CT [13,14], in $89.5 \%$ of HNC patients receiving radiation and in 100\% of HSCT patients [15-19]. Thus in Korea, 18,248 CT patients, 7,646 HNC patients and 1,961 HSCT patients, for a total of 27,855 cancer patients, develop treatment-induced mucositis annually.

The burden of mucositis in terms of costs and survival extends across the spectrum of treatment modalities. In chemotherapy patients with mucositis, $23 \%$ of those with Grade 1 or 2 mucositis and $21 \%$ of those with Grade 3 or 4 mucositis will have unplanned treatment interruptions in the form of dose reductions, treatment delays or cancellations [13,14]. This impacts survival and drives up costs. In HNC patients receiving radiation, $11 \%$ of all mucositis patients require unplanned treatment interruptions [15,20,21]. In this group of mucositis patients (as with others) unplanned treatment delays or dose reductions result in early recurrence of loco-regional disease and a substantial reduction in 5 years survival [3,22-30]. For example, in HNC patients with unplanned treatment breaks occurring during the last week of radiotherapy, the 5 year survival can fall from $65 \%$ to $18 \%$ [4]. In HSCT patients with mucositis, over $11 \%$ die from sepsis due to mucositis-related infections [2,31]. Thus of the 224,177 patients diagnosed and treated for cancer in Korea [10], 27,855 developed clinically significant chemoradiation mucositis that nearly doubles the cost of care $[13,32,33]$. Despite the increase cost expended to treat these patients, still $18.5 \%$ of them, or 5,214 die prematurely due solely to mucositis.

The biological basis for early recurrence of disease and lower overall survival in mucositis patients with unplanned treatment breaks is the phenomenon of tumor cell reproduction following initiation of treatment (chemotherapy or radiation). Approximate 2 weeks following initiation of radiation (or chemotherapy), tumor stem cell repopulation accelerates from a doubling time of 60 days to a doubling time of 4 days $[26,34]$. Thus unplanned breaks due to any cause will result in poor control of local disease, early recurrence of loco-regional disease and lower overall survival [23,26,34]. Noteworthy is the point that once treatment has commenced, maintaining dose intensity - that is, the number of treatments given per unit of time - is critical. For optimal survival treatment schedule established by randomized control trials should not be interrupted nor the dose diluted. Dilution of dose intensity due to mucositis-associated interruptions or reduction of administered dose per treatment contributes directly to early recurrence of malignant disease and the overall reduction in 5 years survival.

Only the elimination of mucositis (ulcerative and non-ulcerative) in patients receiving radiation, chemotherapy or both can reduce the increased cost of care and eliminate the decrease in long-term survival. For 40 years, 1973 to 2013, there has been no Food and Drug Administration (FDA) approved or Korean Food and Drug Administration (KFDA) authorized therapeutic options associated with complete elimination of mucositis in patients undergoing chemoradiation. Oral rinses and sprays - those that are FDA approved (Gelclair, MuGard, Caphosol, Episil) and those that are not (magic mouthwash, honey, etc.) aid in the palliation of discomfort. None eliminate the mucositis disease process. Biologics such as intravenous palifermin (Kepivance) and topical EGF oral spray, though having compelling mechanisms of action, are ineffective in more than $75 \%$ of patients, and does not alter the increased costs of care or mucositis-mediated reduction in survival. These agents fail to meet clinical expectations of patients and practitioners. This lack of confidence in these agents is evident in the number of prescriptions written in 2011 [35] for mucositis in the US, wherein $8.5 \%$ of all 212,785 oral mucositis patients were prescribed an FDA approved anti-mucositis therapy.

In addition to reduced survival and disease-free periods, patients with Grade 2-4 oral, pharyngeal and esophageal mucositis suffer increased morbidity (dehydration, cachexia, nausea, pain, depression, weight loss) and require immediate increased cost of care, generally from surgical insertion of gastrostomy-feeding tubes, unplanned hospitalization and emergency room visits. Undoubtedly only elimination of chemo-radiation-induced mucositis can offer a meaningful therapeutic and economic outcome.

In April 2013, the FDA authorized high potency polymerized cross-linked sucralfate (high potency polymerized cross-linked sucralfate, HPPCLS) in the US for the management- prevention 
and treatment - of oral mucositis. In a post-authorization surveillance study, radiation oncologists used HPPCLS to both prevent and rapidly reverse radiation-induced mucositis in patients [36]. This report covers their experience in prescribing HPPCLS in 55 patients undergoing radiotherapy for squamous cell carcinoma of the head and neck and esophagus.

\section{METHODS}

\section{Materials: anti-mucositis agent used}

\section{High potency polymerized cross-linked sucralfate (ProThelial)}

High potency polymerized cross-linked sucralfate is an FDA cleared medical device therapy used to manage chemoradiation mucositis. It is distinct from commonly available standard potency sucralfate. Standard potency sucralfate studied in the past [37-39] have not be found useful to prevent or reverse oral mucositis or gastrointestinal mucositis and is not recommended for use. Whether in suspension, paste or pill form, standard potency sucralfate is non-polymerized, non-cross-linked and rendered clinically ineffective because it is easily hydrated and dispersed in solution or across the mucosa once administered. The key pharmacologic distinction between standard potency sucralfate and high potency polymerized cross-linked sucralfate is their respective muco-adherence and surface concentrations throughout the gastrointestinal (GI) tract (Table 1).

In the luminal contents of the GI tract surface adherence of standard formulations of sucralfate is undermined by forces of hydration favoring dispersion of molecular sucralfate into luminal contents thus limiting amount of sucralfate available for muco-adhesion. In distinction to standard sucralfate, polymerized and crosslinked sucralfate (PCLS) is a super-structural ionic-bonded amalgamation of sucralfate with two pharmacologic effects. Firstly, following administration non-covalent ionic bonding within PCLS slows simple hydration by water for several hours; secondly inter-molecular cross-linkage and polymerization facilitates the layered accumulation of sucralfate on the mucosal lining. The latter effect contributes directly to the prolonged potency-enhancement of surface-active sucralfate by 7 fold on normal lining and by 23 fold on mucosal lining that is inflamed, eroded or ulcerated.

\section{High potency versus standard potency}

The entire clinical effect of sucralfate is inextricably linked to the surface concentration it achieves on the mucosal lining. Table 1 shows comparative mucosal surface concentration of a $10 \%$ solution of standard sucralfate and $10 \%$ solution of PCLS. The enhanced sucralfate concentration achieved and maintained by PCLS reflects its enhanced muco-adherence. Dose-dependent correlation between the surface concentration of sucralfate and the rate and degree of restorative changes in the GI mucosa, have been reported. Hollander et al. [40] demonstrated that the higher the surface concentration of sucralfate on the gastric lining, the greater the associated focal physiological effects on the mucosa in terms of epithelial regeneration, glandular mucus expression and protective prostaglandin secretion. Not surprisingly, enhanced clinical outcomes (rapid mucosal healing) were associated with enhanced surface concentration of sucralfate. Though identical to standard sucralfate in formulaic concentration at 10\%, PCLS consistently achieved substantially higher mucosal accumulation of sucralfate. This observable fact associated with the associated clinical effects (accelerated epithelial regeneration, glandular mucus expression etc), support the definition of potency enhancement. Three hours following dose administration of polymerized cross-linked sucralfate (ProThelial), the mucosal surface concentration maintained is $800 \%$ greater than standard potency sucralfate on normal lining and 2,400\% greater on ulcerated lining [41].

\section{Methods: study design}

\section{Post-authorization surveillance by Mucositis Registry}

This Mucositis Registry study was initiated as part of post-approval requirement of regulatory authorities. This observation study represents proactive monitoring for unanticipated adverse events, patients' acceptance of therapy and treatment outcomes.

Table 1. Surface sucralfate concentration on acid injured \& normal GI mucosa three hour post-dose

\begin{tabular}{lccc}
\hline Gl tract mucosa & 10\% Sucralfate as HPPLCS & 10\% Standard sucralfate suspension & $\begin{array}{c}\text { Increase concentration of } \\
\text { HPPCLS on the Mucosa }\end{array}$ \\
\hline Acid injured Gl mucosa & $82.81 \mu \mathrm{g}$ per sq cm & $3.56 \mu \mathrm{g} \mathrm{per} \mathrm{sq} \mathrm{cm}$ & 23 Fold increase \\
Normal non-injured GI mucosa & $22.01 \mu \mathrm{g} \mathrm{per} \mathrm{sq} \mathrm{cm}$ & $3.12 \mu \mathrm{g} \mathrm{per} \mathrm{sq} \mathrm{cm}$ & 7 Fold increase \\
Pharynx Erosions & $126.24 \mu \mathrm{g}$ per sq cm & $5.26 \mu \mathrm{g} \mathrm{per} \mathrm{sq} \mathrm{cm}$ & 24 Fold increase \\
Distal esophageal erosions & $93.28 \mu \mathrm{g}$ per sq cm & $4.24 \mu \mathrm{g} \mathrm{per} \mathrm{sq} \mathrm{cm}$ & 22 Fold increase \\
Gastric mucosal erosions & $82.81 \mu \mathrm{g}$ per sq cm & $3.56 \mu \mathrm{g} \mathrm{per} \mathrm{sq} \mathrm{cm}$ & 23 Fold increase \\
Colonic mucosal erosions & $94.34 \mu \mathrm{g}$ per sq cm & $3.87 \mu \mathrm{g} \mathrm{per} \mathrm{sq} \mathrm{cm}$ & 24 Fold increase \\
\hline
\end{tabular}

Gl, gastrointestinal; HPPCLS, high potency polymerized cross-linked sucralfate; sq, square. 


\section{Other objectives of Mucositis Registry}

Other objectives of this Mucositis Registry Study were to observe the prescribing pattern of practitioners and health outcomes associated with HPPCLS in an uncontrolled clinical practice setting. Though authorized as a Class I medical device to be applied, swished, gargled and then expectorated, the FDA insisted that clinicians be informed that HPPCLS was safe to swallow up to 4 grams daily for 56 consecutive days.

\section{Performance of registry study}

Ethical approval: This surveillance study was observational involving no element of intervention requiring review by an ethics committee. Observations were made within established oncology practices involving the routine management of mucositis with the informed consent of all participants involved. Observations were collected in a manner that did not invoke risks of harm or stigma to any involved.

\section{Selection of clinicians and patients}

Clinicians (oncologists, mid-level practitioners and oncology nurse specialists) voluntarily responded to national outreach efforts by specialty pharmacies to provide information regarding HPPCLS. Patients with mucositis or those anticipated to develop mucositis were then selected by prescribing clinicians. Besides a full $500 \mathrm{~mL}$ prescriptions, immediate access to HPPCLS was provided through a physician-assigned patient sample program. Physician-assigned samples of HPPCLS (4-7 day $75 \mathrm{~mL}$ supply) were provided at no cost to patients or insurers for the initial management of mucositis.

Inclusion criteria: Any patient identified by a clinician to receive HPPCLS was enrolled in the registry regardless of type of cancer, its stage or the cancer treatment regimen.

Exclusion criteria: Patients with any previously known adverse reaction (e.g., allergy) to sucralfate were excluded.

\section{Physician-assigned named samples}

Patients identified by clinicians were given a $75 \mathrm{~mL} \mathrm{4-7} \mathrm{day} \mathrm{physi-}$ cian-prescribed sample of HPPCLS and received respective patient instruction sheets accordingly. Patients were maintained weekly on assigned samples at the request of the clinician. Depending on the severity of mucositis or management goal (treatment versus prevention) each patient-administered dose ranged from 2.5 to 10.0 $\mathrm{mL}$ of paste.

\section{Instruction for use}

The adult dose of HPPCLS administered was determined by both the intent of management (prevention versus reversal) and by the anticipated or known grade of mucositis (discussed in next section). Dosing used is described in Table 2. Patients were instructed to use their tongue to apply dose to all surfaces inside mouth, then gargle for 10 seconds, hold in their mouth for 15 seconds and then expectorate or swallow if so instructed by their oncologist. If tongue application was not possible, then cotton tipped swabs were used to apply HPPCLS onto all oral surfaces, followed by gargling and holding in mouth for 15 seconds. Patients were informed by clinicians that HPPCLS was safe to swallow, in patients (age 12 and older) 1 gram four times daily for up to 56 continuous days. Patients younger than 12 (not in this report), could use HPPCLS, swish, expectorate or swallow as directed by pediatric oncologist; generally no more than $14 \mathrm{mg} / \mathrm{kg} /$ dose two to three times daily depending on severity of mucositis developed or anticipated.

\section{Assessing grade of mucositis}

Grade and functions related to difficulty with eating, drinking, swallowing, nausea vomiting and diarrhea were identified by the clinical staff prescribing HPPCLS and confirmed by follow up phone calls of registry attendants. The functional patient-reported scale of the World Health Organization (WHO) [42] and the European Organization for Research and Treatment of Cancer/Radiation Therapy Oncology Group (EORTC/RTOG) grading scale [43] were used (Table 3).

\section{Outcomes collection}

Outcomes data were collected by registry attendants through calls made to clinical practices and to patients. All information was collected within four to seven days of patients' initial use of HPPCLS.

Table 2. Proposed single agent protocol using ProThelial for chemo-radiation induced mucositis

\begin{tabular}{|c|c|c|c|}
\hline Management goal & Cancer therapy & Loading dosing & Maintenance dosing through 1 week post-cancer therapy \\
\hline Treatment Grade 1, 2 & Chemo-radiation & 2.5 to $5 \mathrm{~mL}$ TIDx1 day (250-500 mg) & 2.5 to $5 \mathrm{~mL} \mathrm{BID} \mathrm{(250-500} \mathrm{mg)}$ \\
\hline Treatment Grade 3, 4 & Chemo-radiation & 10 mL TIDx2 days (1,000 mg) & 5 to $10 \mathrm{~mL} \mathrm{BID}(500-1,000 \mathrm{mg})$ \\
\hline Prevention Grade 1, 2 & Chemo-radiation & 2.5 to $5 \mathrm{~mL}$ TIDx1 day (250-500 mg) & 2.5 to $5 \mathrm{~mL} \mathrm{BID} \mathrm{(250-500} \mathrm{mg)}$ \\
\hline Prevention Grade 3, 4 & Chemo-radiation & 10 mL TIDx2 days $(1,000$ mg) & 10 mL TID (1,000 mg) \\
\hline
\end{tabular}

Prevention regimen start first day of cancer treatment.

TID, three times daily; BID, twice daily. 
Table 3. EORTCRTOG \& WHO toxicity criteria acute chemo-radiation mucositis morbidity

\begin{tabular}{|c|c|c|c|c|c|}
\hline & \multirow{2}{*}{ Grade 0} & \multicolumn{4}{|c|}{ Oral \& GI toxicity scale } \\
\hline & & Grade 1 & Grade 2 & Grade 3 & Grade 4 \\
\hline $\begin{array}{l}\text { WHO } \\
\text { Oral mucosal toxicity } \\
\text { grade }\end{array}$ & None & $\begin{array}{l}\text { Painless ulcers, erythema or } \\
\text { mild soreness with swal- } \\
\text { lowing liquid, hard \& soft } \\
\text { solids }\end{array}$ & $\begin{array}{l}\text { Painful erythema, edema, or } \\
\text { ulcers but can eat only soft } \\
\text { solids \& liquids }\end{array}$ & $\begin{array}{l}\text { Painful erythema, edema, or } \\
\text { ulcers and cannot eat sol- } \\
\text { ids, barely drink liquids }\end{array}$ & $\begin{array}{l}\text { Alimentation is not possible; } \\
\text { dependence on IV \& feed- } \\
\text { ing-tube }\end{array}$ \\
\hline $\begin{array}{l}\text { EORTCRTOG } \\
\text { Esophagus toxicity grade }\end{array}$ & None & $\begin{array}{l}\text { Mild fibrosis; slight difficulty } \\
\text { in swallowing solids; no } \\
\text { pain on swallowing }\end{array}$ & $\begin{array}{l}\text { Unable to take solid food } \\
\text { normally; Swallowing } \\
\text { semi-solid food; Dilation } \\
\text { may be indicated }\end{array}$ & $\begin{array}{l}\text { Severe fibrosis; Able to swal- } \\
\text { low only liquids; May have } \\
\text { pain on swallowing dila- } \\
\text { tion required }\end{array}$ & Necrosis/perforation fistula \\
\hline $\begin{array}{l}\text { EORTCRTOG } \\
\text { Small bowel toxicity grade }\end{array}$ & None & $\begin{array}{l}\text { Mild diarrhea; mild cramp- } \\
\text { ing; bowel movement } 5 \\
\text { times daily }\end{array}$ & $\begin{array}{l}\text { Moderate diarrhea and colic; } \\
\text { Bowel movement }>5 \\
\text { times daily }\end{array}$ & $\begin{array}{l}\text { Obstruction or bleeding, re- } \\
\text { quiring surgery }\end{array}$ & Necrosis/perforation fistula \\
\hline $\begin{array}{l}\text { EORTCRTOG } \\
\text { Colorectal toxicity grade }\end{array}$ & None & $\begin{array}{l}\text { Increased frequency or } \\
\text { change in quality of bowel } \\
\text { habits not requiring; } \\
\text { Medication, rectal discom- } \\
\text { fort not requiring analge- } \\
\text { sics; Slight rectal discharge } \\
\text { or bleeding }\end{array}$ & $\begin{array}{l}\text { Diarrhea requiring parasym- } \\
\text { patholytic drugs, mucous } \\
\text { discharge not necessitat- } \\
\text { ing sanitary pads, rectal or } \\
\text { abdominal pain requiring } \\
\text { analgesics; Excessive rectal } \\
\text { mucus or intermittent } \\
\text { bleeding }\end{array}$ & $\begin{array}{l}\text { Diarrhea requiring parenter- } \\
\text { al support, severe mucous } \\
\text { or bloody discharge neces- } \\
\text { sitating sanitary pads/ab- } \\
\text { dominal distension (flat } \\
\text { plate radiograph demon- } \\
\text { strates distended bowel } \\
\text { loops) }\end{array}$ & $\begin{array}{l}\text { Acute or subacute obstruc- } \\
\text { tion, fistula or perforation; } \\
\text { gastrointestinal bleeding } \\
\text { requiring transfusion; ab- } \\
\text { dominal pain or tenesmus } \\
\text { requiring tube decompres- } \\
\text { sion or bowel diversion }\end{array}$ \\
\hline $\begin{array}{l}\text { WHO } \\
\text { Colorectal toxicity grade }\end{array}$ & None & $\begin{array}{c}\text { Increase of 2-3 stools per } \\
\text { day over Pretreatment }\end{array}$ & $\begin{array}{l}\text { Increase of 4-6 stools per d, } \\
\text { or nocturnal stools, or } \\
\text { moderate cramping }\end{array}$ & $\begin{array}{l}\text { Increase of 7-9 stools per } \\
\text { day, or incontinence, or se- } \\
\text { vere cramping }\end{array}$ & $\begin{array}{l}\text { Increase of > } 10 \text { stools per } \\
\text { day or grossly bloody diar- } \\
\text { rhea, or need for parenter- } \\
\text { al support }\end{array}$ \\
\hline
\end{tabular}

EORTC/RTOG, European Organization for Research and Treatment of Cancer/Radiation Therapy Oncology Group; WHO, World Health Organization; Gl, gastrointestinal.

Staff and patients were specifically asked regarding the timing of clearance of symptoms and signs of mucositis, if any, with a focus on the presence or absence of symptoms or signs on days 1,2,3, and 4 .

\section{RESULTS}

\section{Registry characteristics}

The Mucositis Registry was populated from February 10 through December 30, 2014 and included 66 sequentially enrolled patients, with 55 patients receiving radiotherapy as part of their cancer treatment which are reported here.

\section{Registry clinicians and institutions}

There were 28 radiation oncologists from 21 different oncology institutions across the US.

\section{Registry institutions}

There were 21 participating institutions across 12 states in the US including Connecticut, Florida, Georgia, Illinois, Kansas, Massachusetts, Maine, Michigan, Pennsylvania, Rhode Island, Tennessee and South Carolina. The type of oncology practices included $\mathrm{Na}$ tional Cancer Institute (NCI) designated facilities $(\mathrm{n}=4)$, NCCN practices $(\mathrm{n}=2)$, hospital-based institutions $(\mathrm{n}=11)$, and community-based practices $(n=4)$.

\section{Registry patients}

Of the 55 patients completing follow up, 47 were prescribed HPPCLS for treatment (reversal) of mucositis, while 8 were prescribed HPPCLS for prevention of mucositis. All patients had either undergone or were to undergo chemotherapy, radiation or combined chemo-radiation for cancer treatment. There were no HSCT patients. Of these 55 patients requiring radiotherapy for squamous cell carcinoma, 53 had malignancies of the head and neck and 2 of the esophagus. Eight of these patients received HPPCLS to prevent mucositis and avoid surgical placement of a gastrostomy feeding tube. The remaining 47 were prescribed HPPCLS to treat (reverse) mucositis. Overall there were 55 consecutive patients in the registry 42 males (age, 49 to 93) and 13 females (age range, 14 to 84). No adverse reactions were encountered and HPPCLS was well tolerated which met the main objective of this post-approval surveillance study. 
Table 4. Baseline types (Location) and grades mucositis in radiotherapy patients

\begin{tabular}{llcll}
\hline Location mucositis & Grade & $\begin{array}{c}\text { No. of } \\
\text { patients }\end{array}$ & Grade system \\
\hline Oral mucositis & Grade 1 & 6 & WHO \\
& Grade 2 & 23 & WHO \\
& Grade 3 & 16 & WHO \\
& Grade 4 & 0 & WHO \\
Esophageal mucositis & Grade 2 & 10 & WHO/EORTC-RTOG \\
Small bowel mucositis & Grade 2 & 6 & WHO/EORTC-RTOG \\
Colonic mucositis $^{\text {a) }}$ & Grade 2/3 & 6 & WHO/EORTC-RTOG \\
\hline
\end{tabular}

WHO, World Health Organization; EORTC-RTOG, European Organization for Research and Treatment of Cancer/Radiation Therapy Oncology Group.

a) Some patients had mucositis in several anatomical areas (oral, esophageal, small bowel and colon).

\section{Types of cancers in registry}

The type of cancers receiving radiotherapy in the registry included unspecified squamous cell carcinoma (SCC) of the head and neck $(\mathrm{n}=18)$, SCC of the tonsil $(\mathrm{n}=10)$, SCC of the tongue $(\mathrm{n}=12)$, SCC of the oral cavity $(n=7)$, SCC of the larynx $(n=6)$, and esophageal cancer $(\mathrm{n}=2)$.

\section{Types of radiation treatment in registry}

Most patients $(\mathrm{n}=54)$ received standard radiotherapy while 1 received intensity-modulated radiotherapy.

\section{Baseline grades of mucositis}

The WHO scale for oral mucositis and the EORTC/RTOG and WHO Scale for GI Toxicity were used to grade the 47 patients with mucositis. The number of patients per grade and location of mucositis is shown in Table 4. The use of other anti-neoplastic treatments (mentioned below) led to both oral and gastrointestinal mucositis.

\section{Other cancer treatments associated with mucositis in this study}

In this study patients besides the two forms of radiotherapy (non-IMRT and IMRT) many had received several other types of anti-neoplastic agents (Table 5). These include targeted immunotherapies (ipilimumab, novilumab, cetuximab) and traditional non-targeted CT agents (folinic acid, 5-fluorouracil, irinotecan, oxaliplatin, carboplatin, paclitaxel). These treatments have different mechanisms of action that contribute to the development of mucositis which may occur in different anatomical sites within the GI tract.

\section{Baseline anti-mucositis interventions used by clinicians}

Historically the 24 of 28 practitioners of this registry had managed
Table 5. Type of treatments creating mucositis in 55 head neck cancer patients

Radiation therapy
Standard radiation in $54 / 55$ patients
Intensity-modulated radiation in $1 / 55$ patient
Targeted immunotherapies
Ipilimumab
Novilumab
Cetuximab
Non-targeted cytotoxic agents
Folinic acid
5 Fluorouracil
Irinotecan
Oxaliplatin
Carboplatin
Paclitaxel

mucositis with mouth rinses (FDA approved ones and magic mouthwash), antacids, oral hygiene, generic sucralfate suspension or cryotherapy. The remaining practitioners had no treatment preferences. None were satisfied with current interventions, as persisting mucositis limited their ability to maintain optimal dosing without unplanned interruption of radiation treatment.

\section{Mucositis prevention patients (feeding tube anticipated)}

Eight patients without mucositis were prescribed HPPCLS because oncologists anticipated the development of mucositis severe enough to contemplate prophylactic placement of a gastrostomy feeding tube. These included 6 males (ages, 78-93) and 2 females (ages, 74, 84) who were assigned baseline grade 0 mucositis, pretreatment. Three patients had oral cancer, two with tonsillar, two with lingular and one with laryngeal cancer.

\section{Registry outcomes for radiotherapy patients Clinician practice outcomes}

There were 28 radiation oncologists from 21 different oncology institutions in the US who prescribed HPPCLS to 47 patients with existing mucositis and to 8 patients anticipated to develop oral and esophageal mucositis. In the latter intent-to-prevent group of patients, clinicians sought to avert placement of gastrostomy feeding tube. All patients were at-risk for mucositis-associated unplanned interruption of radiotherapy. All patients were instructed to swallow HPPCLS (an off-label procedure) rather than expectorate following tongue application and gargling.

\section{Oral and esophageal mucositis outcome}

Each of the 47 radiotherapy patients, 45 with oropharyngeal mu- 
Table 6. Radiotherapy patients with SCC using HPPCLS in registry to eliminate/prevent mucositis

\begin{tabular}{|c|c|c|c|c|}
\hline Cancer type & No. of patients & Therapy & Elimination agent & Mucositis $^{a)}$ \\
\hline \multicolumn{5}{|l|}{ For mucositis reversal } \\
\hline SCCHN (undifferentiated) & 18 & Radiation (\& chemo) & HPPCLS & 2-3 Day elimination \\
\hline SCCHN (tongue) & 10 & Radiation (\& chemo) & HPPCLS & 2-3 Day elimination \\
\hline SCCHN (tonsil) & 8 & Radiation ( \& chemo) & HPPCLS & 2-3 Day elimination \\
\hline SCCHN (oral cavity) & 4 & Radiation (\& chemo) & HPPCLS & 2-3 Day elimination \\
\hline SCCHN (larynx) & 5 & Radiation (\& chemo) & HPPCLS & 2-3 Day elimination \\
\hline Esophageal & 2 & Radiation (\& surgery) & HPPCLS & 2-3 Day elimination \\
\hline \multicolumn{5}{|l|}{ For mucositis prevention } \\
\hline Tongue (SCCHN) & 2 & Radiation ( \& chemo) & HPPCLS & Complete prevention \\
\hline Oral cavity (SCCHN) & 3 & Radiation (\& chemo) & HPPCLS & Complete prevention \\
\hline Larynx (SCCHN) & 1 & Radiation ( \& chemo) & HPPCLS & Complete prevention \\
\hline Tonsil (SCCHN) & 2 & Radiation (\& chemo) & HPPCLS & Complete prevention \\
\hline
\end{tabular}

SCC, squamous cell carcinoma; HPPCLS, high potency polymerized cross-linked sucralfate; SCCHN, squamous cell carcinoma of head \& neck.

a) Some patients still experienced dry mouth (salivary gland dysfunction), altered taste and dental issues. None of these are related to disruption of the mucosal lining of oral, pharyngeal and esophageal cavity.

Table 7. Radiotherapy patients with SCC using HPPCLS in registry to prevent mucositis

\begin{tabular}{lcccc}
\hline Cancer type & Number of patients & Therapy & Prevention agent & Mucositis \\
\hline SCCHN (tongue) & 2 & Radiation $(\&$ chemo) & HPPCLS & G-tube averted \\
SCCHN (tonsil) & 2 & Radiation $(\&$ chemo) & HPPCLS & G-tube averted \\
SCCHN (oral) & 3 & Radiation $(\&$ chemo) & HPPCLS & G-tube averted \\
SCCHN (larynx) & 1 & Radiation $(\&$ surgery) & HPPCLS & G-tube averted \\
\hline
\end{tabular}

SCC, squamous cell carcinoma; HPPCLS, high potency polymerized cross-linked sucralfate; SCCHN, squamous cell carcinoma of head \& neck.

cositis (OPM) and 2 with esophageal mucositis, experienced complete reversal, that is, complete elimination of mucositis with restoration of normal mucosa within 2-3 days (Table 6).

\section{Prevent mucositis/avert tube outcome}

There were 8 radiotherapy patients, mostly elderly, 6 men age 78 93 and 2 women, ages 74 and 84 who were to undergo treatment for SCCHN. Each was to require prophylactic placement of feeding tube for anticipated Grade 3 or 4 oral and esophageal mucositis. These patients started HPPCLS on or 1-2 days prior to therapy. None developed mucositis throughout entire radiation treatment while on HPPCLS. Tables 6 and 7 summarize their outcomes.

\section{Prevent of mucositis-associated unplanned interruption outcome}

Of the 55 patients likely to develop mucositis, 55 were at risk of mucositis-associated unplanned interruption. There were $47 \mathrm{pa}-$ tients who developed mucositis and at risk of mucositis-associated unplanned interruption and 8 elderly patients were anticipated to have unplanned treatment breaks due to high likelihood of developing Grade 3 or 4 mucositis. Of the 47 patients who developed mucositis and was anticipated to have unplanned treatments breaks, all episodes of mucositis were eliminated and there were no unplanned treatment breaks, though $11 \%$ or 5 to 6 patients should have $[15,20,21]$. All 8 radiotherapy patients prescribed HPPCLS to prevent mucositis and avoid unplanned breaks, experienced no mucositis-associated breaks in therapy and avoided surgical placement of gastrostomy feeding tubes.

\section{Non-mucositis sypmtoms experienced outcome}

Non-mucositis symptoms experienced by patients include, drymouth, altered taste and dental issues. These symptoms were not related to mucositis, that is the disruption of buccal, pharyngeal and esophageal mucosa.

\section{Eleven case series exemplifying efficacy of hppcls (ProThelial)}

Table 8 exemplifies the typical outcomes of HPPCLS in 11 different patients, eight treated to reverse mucositis and 3 treated to prevent the onset of mucositis. In these patients with either oral, esophageal, small bowel or colonic mucositis there was rapid and complete reversal of mucositis during cancer treatment. In three of these patient examples mucositis was completely prevented during cancer treatment and the placement of prophylactic gastrostomy 
Table 8. Eleven case series from phase IV post-market surveillance of ProThelial

\begin{tabular}{|c|c|c|c|c|c|c|}
\hline Age $(y r) / S e x$ & Cancer type & $\begin{array}{c}\text { Time from start } \\
\text { of cancer treatment }\end{array}$ & Institution & $\begin{array}{l}\text { Grade of } \\
\text { mucositis }\end{array}$ & Location of mucositis & Therapeutic outcome \\
\hline \multicolumn{7}{|c|}{ Complete reversal during chemo-radiation } \\
\hline 49/Male & SCC tonsil & $\begin{array}{l}4 \text { weeks of cetuximab plus } \\
\text { radiation }\end{array}$ & $\begin{array}{l}\text { Swedish } \\
\text { Covenant } \\
\text { Hospital } \\
\text { Chicago, IL }\end{array}$ & Grade 3 & Oropharyngeal & 2-3 Day elimination \\
\hline 56/Male & $\begin{array}{l}\text { SCC } \\
\text { oropharyngeal }\end{array}$ & $\begin{array}{l}4 \text { weeks radiation and } \\
\text { unspecified chemotherapy }\end{array}$ & $\begin{array}{l}\text { Ocala, FL } \\
\text { Radiation Oncology }\end{array}$ & Grade 3 & Oropharyngeal & 2-3 Day elimination \\
\hline 88/Male & SCCHN & $\begin{array}{l}3 \text { weeks } \\
\text { cetuximab+radiation }\end{array}$ & $\begin{array}{l}\text { Ocala, FL } \\
\text { Radiation Oncology }\end{array}$ & Grade 3 & Oropharyngeal & 2-3 Day elimination \\
\hline 52/Male & $\begin{array}{l}\text { Stage IV } \\
\text { pancreatic }\end{array}$ & 2 weeks Folfirinox & $\begin{array}{l}\text { Lexington } \\
\text { Oncology } \\
\text { South Carolina }\end{array}$ & Grade 2 & $\begin{array}{l}\text { Oral mucositis } \\
\text { BMS } \\
\text { Esophageal mucositis }\end{array}$ & $\begin{array}{l}\text { 2-3 Day elimination } \\
\text { (held in mouth longer to relieve } \\
\text { BMS) } \\
\text { Swallowed ProThelial }\end{array}$ \\
\hline 49/Male & $\begin{array}{l}\text { Stage IV } \\
\text { pancreatic }\end{array}$ & 8 weeks Folfirinox & $\begin{array}{l}\text { Vanderbilt } \\
\text { Tennessee }\end{array}$ & $\begin{array}{l}\text { Grade } 4 \\
\text { Feed-Tube } \\
\text { Dependent }\end{array}$ & $\begin{array}{l}\text { Esophageal } \\
\text { Small bowel } \\
\text { Colonic mucositis }\end{array}$ & $\begin{array}{l}\text { 2-3 Day elimination of } \\
\text { esophageal mucositis } \\
4 \text { Day reversal } \\
\text { SB/Colonic off tube feeding } 3 \text { days } \\
\text { Swallowed ProThelial }\end{array}$ \\
\hline 49/Female & $\begin{array}{l}\text { Stage IV } \\
\text { metastatic } \\
\text { melanoma }\end{array}$ & $\begin{array}{l}4 \text { weeks ipilimumab } \\
\text { plus nivolumab }\end{array}$ & $\begin{array}{l}\text { Yale } \\
\text { New Haven }\end{array}$ & Grade 3 & $\begin{array}{l}\text { Oral } \\
\text { Small bowel } \\
\text { Colonic mucositis }\end{array}$ & $\begin{array}{l}\text { 3-4 Day elimination } \\
\text { Swallowed ProThelial }\end{array}$ \\
\hline 62/Male & $\begin{array}{l}\text { SCC } \\
\text { esophagus }\end{array}$ & $\begin{array}{l}6 \text { weeks radiation with } \\
\text { pactlitaxel/carboplatin }\end{array}$ & $\begin{array}{l}\text { St Frances } \\
\text { Cancer Ctr } \\
\text { Hartford, CT }\end{array}$ & Grade 3 & Esophageal mucositis & $\begin{array}{l}\text { 2-3 Day elimination } \\
\text { Swallowed ProThelial }\end{array}$ \\
\hline 52/Female & $\begin{array}{l}\text { Recurrent } \\
\text { ovarian cancer }\end{array}$ & $\begin{array}{l}2 \text { weeks radiation, with } \\
\text { carboplatin }\end{array}$ & $\begin{array}{l}\text { Univ Pittsbg } \\
\text { Medical Ctr }\end{array}$ & Grade 3 & Oral mucositis & $\begin{array}{l}\text { 2-3 Day elimination } \\
\text { Swallowed ProThelial }\end{array}$ \\
\hline \multicolumn{7}{|c|}{ Complete prevention during chemo-radiation } \\
\hline 93/Male & SCC tongue & 0 weeks radiation only & $\begin{array}{l}\text { Kansas } \\
\text { Radiation Oncology }\end{array}$ & $\begin{array}{l}\text { Anticipated } \\
\text { Grade } 4\end{array}$ & $\begin{array}{l}100 \% \text { Anticipated } \\
\text { requirement of feeding } \\
\text { G-tube }\end{array}$ & $\begin{array}{l}\text { G-tube averted } \\
\text { None required while on ProThelial } \\
\text { Swallowed ProThelial }\end{array}$ \\
\hline 78/Male & SCC tongue & 0 weeks radiation only & $\begin{array}{l}\text { Kansas } \\
\text { Radiation Oncology }\end{array}$ & $\begin{array}{l}\text { Anticipated } \\
\text { Grade } 4\end{array}$ & $\begin{array}{l}100 \% \text { Anticipated } \\
\text { requirement of feeding } \\
\text { G-tube }\end{array}$ & $\begin{array}{l}\text { G-tube averted } \\
\text { None required while on ProThelial } \\
\text { Swallowed ProThelial }\end{array}$ \\
\hline 68/Male & SCC tongue & $\begin{array}{l}0 \text { weeks radiation and } \\
\text { unspecified chemotherapy }\end{array}$ & $\begin{array}{l}\text { Kansas } \\
\text { Radiation Oncology }\end{array}$ & $\begin{array}{l}\text { Anticipated } \\
\text { Grade } 4\end{array}$ & $\begin{array}{l}100 \% \text { Anticipated } \\
\text { requirement of feeding } \\
\text { G-tube }\end{array}$ & $\begin{array}{l}\text { G-tube averted } \\
\text { None ile on ProThelial } \\
\text { Swallowed ProThelial }\end{array}$ \\
\hline
\end{tabular}

SCC, squamous cell carcinoma; reversal, mucositis elimination; SCCHN, squamous cell carcinoma of head \& neck; BMS, burning Mouth Syndrome.

tube was averted. HPPCLS had the same effect in prevention and reversal of mucositis regardless of its cause. In Table 8 are eight patients who received combination chemo-radiation (cetuximab, folfirinox, iplimumab, nivolumab, paclitaxel, carboplatin) who developed small bowel and colonic mucositis as well. The instructive point of this Table 8 is the following. While treatment modalities have different mechanisms of action leading to development of mucositis occurring a different anatomical sites within the GI tract, HPPCLS demonstrated capacity to completely and rapidly reverse mucositis regardless of the agent causing it and regardless of the anatomical location of the occurrence of mucositis.

\section{Statistical analysis}

\section{Confounding bias, treatment effect size}

Confounding biases (trial size, selection, blinding and protocol biases) can overwhelm the magnitude of treatment effects of most anti-mucositis agents. Therefore well designed, adequately powered, randomized placebo-controlled trials are an absolute necessity. This is because the size of treatment effect from any single intervention will include the placebo effect, which can range from 15 to 30 base points or $15 \%$ to $30 \%$. The relatively small treatment size published for most anti-mucositis interventions are reported in settings controlled to minimize the effect of confounding biases, as 
the latter, if not controlled can overwhelm (diminish or exaggerate) the magnitude of the treatment effect. As an aggregate, the size of the treatment effect (within which is the placebo effect) with the effect size of confounding factors are generally well under 100 base points. If however the size of the treatment effect is 1,000 base points or greater compared to that of standard outcomes or placebo then the lack of controlling confounding biases that never exceed 100 base points will not affect the overall conclusion that a large treatment effect size, one that is 1,000 base points beyond expected, could explain such an outcome.

Indeed, this is the situation for this uncontrolled low powered observational study. Complete prevention of mucositis (zero days departure from baseline) when it should have developed or the rapid reversal of mucositis - 2 to 3 days to return to baseline using HPPCLS - compared to the standard 84 days to return to baseline is a treatment effect whose size cannot be explained by uncontrolled confounding factors.

This is particularly true since, no anti-mucositis intervention to date (less alone any uncontrolled confounding bias) has consistently and repeatedly been associated with the treatment effect of complete prevention that is zero days departure from baseline of normal mucosa during radiation treatment. Additionally, no anti-mucositis intervention to date, regardless of its mechanism of action has consistently and repeatedly been associated with shortening time to baseline during ongoing radiation therapy from 84 days to $2-3$ days.

\section{Rate ratio of the Glasziou treatment effect}

Regardless of the anti-mucositis intervention used, patient-reported duration of oral mucositis, once established during radiotherapy, will predictably persists for 70-84 days for SCCHN patients $[16,17]$ before returning to baseline and that only after cessation of treatment. In this study, patient-reported Grade 2, 3 oral mucositis reversed in 2-3 days in all patients treated with HPPCLS while actively undergoing radiation treatment. This magnitude of treatment effect occurred repeatedly (47 times) without regard to type of cancer treatment causing mucositis, or the anatomical location of the mucositis. Additionally, all eight patients treated for prevention of mucostis, were completely protected from the onset of mucositis though anticipated. They experience zero-days departure from normal oral mucosa throughout radiation therapy. Dry mouth (salivary gland dysfunction), altered taste and dental effects were not related to mucosal disruption of the oral, pharyngeal or esophageal lining.

The rate ratio resulting from comparing expected time-to-event values (patient-reported reversal of mucositis) to those generated by HPPCLS was 68, far greater than the statistical threshold of 10 required for a positive Glasziou treatment effect [44].

The Glasziou rate ratio in this study, comparing the HPPCLS time-to-event (2.5 days) to the expected time-to-event ( 84 days) for patient-reported resolution of mucositis and can be calculated as follows:

Rate for HPPCLS $\div(0.5 \div$ days for mucositis to resolve $)=$ rate ratio $(1 \div 2.5$ days $) \div(0.5 \div 84$ days $)=67.8$

The clinical outcome from HPPCLS demonstrates a quantifiable effect that is statistically beyond that expected $(\mathrm{P} \leq 0.05)$ for the course of patient-reported mucositis under treatment by any other anti-mucositis intervention.

None of the interventions recommended by the Multi-national Association of Supportive Cancer Care (MASCC) have been associated with complete prevention or rapid and complete elimination of mucositis, typically leaving $60 \%-75 \%$ of mucositis unaffected, though there was intent to reverse or prevent all patients tested. Every patient treated with HPPCLS had a complete response, a treatment effect size associated with rate ratios far beyond ' 10 ', the number required to secure assumption of efficacy beyond confounding biases.

\section{Quality of HPPCLS evidence}

Randomized, placebo-controlled and blinded studies are considered Level I quality of evidence while non-randomized, uncontrolled observational studies with no blinding (such as in this report) are considered the lower Level IV/V quality $[45,46]$.

This is because, historically, the magnitude of the treatment effect for most mucositis interventions is similar to that of a placebo, and in a minority of cases the magnitude of treatment effect is equivalent to no treatment at all. Therefore for most anti-mucositis agents confounding biases must be minimized using randomization, blinding and placebos. For the most part, the magnitude of treatment effect for treatment interventions are only $30-50$ base points better than placebo [47] and every treatment effect contains its own placebo effect contributing to its efficacy. This may be referred to as the 'common range of outcomes'.

It is infrequent and atypical that the magnitude of treatment effect for an intervention will be 10 times (or greater) than this 'common range of outcomes, and if it is, then it is highly unlikely that confounding factors influenced the outcome. Guyatt et al. [45] asserted that "the larger the magnitude of effect, the stronger becomes the evidence" and that "the presence of a dose-response gradient" or a "very large (treatment) effect suggests a rating of high quality evidence".

\section{Relative risk ratios}

The therapeutic effects of palifermin, mouth rinses and other 
MASCC-guideline supported options while better than placebo, have not been associated with rate ratios beyond 1. Patient-reported duration of Grade, 1, 2, and 3 oral mucositis during cancer treatment persisted in more than $60 \%$ of patients treated with palifermin in controlled trials [48], and in more than $75 \%$ of patients treated with multiple MASCC supported interventions [49]. Although these patients received myeloablative doses of chemotherapy, it is highly unlikely (though possible) that associated cases of Grade 1,2, and 3 oral mucositis are physiologically distinct from those caused by non-myeloablative doses of chemotherapy, such that a therapeutic intervention effective for Grade 1-3 oral mucositis due to non-myeloablative doses of chemotherapy would be completely ineffective for Grade 1-3 oral mucosits caused by myeloablative doses of chemotherapy. Physiologically, Grade 1-3 oral mucositis should be indistinguishable on the basis of the mucositogenic agent causing the injury.

Based on this consideration, the relative risk of some patients remaining unresponsive to an anti-mucositis treatment could be calculated. In the trials reported by Spielberger et al. [48] using palifermin and Bhatt et al. [49] using seven different anti-mucositis agents, the proportion of patients remaining unaffected by use of respective interventions was 0.63 and 0.75 , respectively. In all 47 consecutive patients reported here wherein the intent was complete reversal and in 8 patients wherein the intent was complete prevention there were no patients unaffected by HPPCLS. Since over a 10 month period of time, 47 and 8 consecutively enrolled patients treated by 28 different oncologists, failed to be non-responsive, it seems reasonable to assume that, should the study continue without end 0.05 patients [44] may be found to be unaffected by the use of HPPCLS.

The relative risk of using standard therapies compared to HPPCLS would then be 0.63 and 0.75 (using non-HPPLCS agents) divided by 0.05 (using HPPCLS) or 12.6 and 15 respectively. According to Guyatt et al. [45] and Oxman [46] if the relative risk ratio is greater than 2, then there is strong evidence of association, and if greater than 5 then there is "very strong evidence of association". In other words, despite the uncontrolled low powered design of this observational study, the magnitude of the treatment effect observed with HPPCLS supports probable efficacy.

\section{Significance of prevention outcomes}

Eight elderly patients all with SCCHN intended to receive prophylactic placement of gastrostomy tubes experienced complete prevention using HPPCLS, averting anticipated and otherwise required placement of feeding tubes. While this number, $\mathrm{n}=8$, is low, the magnitude of the HPPCLS treatment effect elevate these outcomes into significance. Similar to the category of treatment effect observed with physostigmine administered to a single patient with myasthenia gravis, if the outcome is repeated more than once, the outcome is medically significant, based on the known plausible mechanism of action. It is highly unlikely that the administration of any intervention could repeatedly prevent oral, pharyngeal and esophageal mucositis in multiple patients at high risk of developing it.

\section{DISCUSSION}

This study, limited as it was in design (real-world, observational and uncontrolled) reports treatment outcomes whose effect size and magnitude could not be attributed to the work of uncontrolled confounding factors of bias. That is, the lack of randomization, blinding, and controls treatment would not have contributed to the size of treatment effect observed repeatedly in 28 different oncology practices in 21 different institutions across 12 different geographic states.

Generally, because the treatment effect size of most interventions rarely exceed 30-60 base points beyond placebo [47] the potential influence of confounding factors in trials, which unpredictably may range from 3 to 30 base points, require control, blinding and randomization. However with or without controlling these factors, it is highly unlikely that the 68 fold effect size difference between observed outcomes using HPPCLS and expected outcomes using other agents was due, in part or as a whole, to exaggerated effects of uncontrolled factors or biases, as discussed in the statistical analysis.

Indeed, until now, there has been no report of complete elimination of mucositis-associated unplanned breaks using an FDA approved anti-mucositis agent. Additionally, though partial mitigation of anticipated Grade 3 to Grade 4 oropharyngeal mucositis has been report with palifermin and other agents [48,49], complete prevention has not been reported apart from HPPCLS. Neither have there been reports of rapid nor complete reversal of orapharyngeal and esophageal mucositis once established and that elimination of mucositis persists in the patient continuing radiotherapy. Apart from HPPCLS, normalization of the mucosa during active chemo-radiation previously involved in ulcerative mucositis, has not been reported.

These three therapeutic outcomes - (a) the elimination of mucositis-associated breaks in radiotherapy, (b) complete prevention of anticipated mucositis, and (c) the rapid (complete) reversal of mucositis with normalization of the orapharyngeal and esophageal function and appearance during chemoradiation - are new and likely transformative. 


\section{Significance of HPPCLS outcomes}

The significance of these outcomes are better understood when considered in the context of the mucositis guidelines of MASCC. Additionally, the history in Korea on other approved anti-mucositis products, namely MuGard, Episil and EGF oral sprays, also provide context. In general, all therapeutic options (mouth rinses, palifermin, low level laser treatment etc.) whether authorized by regulators (FDA or KFDA), or supported by MASCC guidelines as off-label options have had only fractional impact on the overall incidence of mucositis and negligible effect on course of mucositis, the deaths it mediates and the increased cost of care that it invites.

\section{Therapeutic options in MASCC guidelines}

While several mucositis guidelines have been published [50-52] the MASCC guidelines are most widely cited $[53,54]$. The 12 ther- apeutic interventions in the 2014 MASCC mucositis guidelines for oral and gastrointestinal mucositis are listed in Table 9. Randomized control trials have demonstrated that these interventions provide only fractional and clinically insignificant difference in the overall effects that mucositis has on survival and increased costs of cancer care. None of the 12 interventions provide complete prevention or rapid and complete reversal.

Informative as it may be, the guidelines provide little by way of practical guidance in the uncontrolled clinical setting. For oral mucositis (OM) ulcerations, there are four 'recommendations' and three 'suggestions' favoring the use of five different interventions for a total of seven. All seven supportive positions are for interventions to prevent the onset of OM. There are none recommended for the treatment or reversal of OM. For oral mucositis pain, there is one recommendation and four suggestions favoring

Table 9. MASCC guideline recommendation/suggestions for 2014

\begin{tabular}{|c|c|c|c|c|c|c|}
\hline Intervention & Dose/timing & Route & Indication & Intent & Cancer treatment & Other controlling conditions \\
\hline \multicolumn{7}{|c|}{ Gastrointestinal mucositis } \\
\hline Amifostine & Unmentioned & IV & GIM-esophagitis & Prevention & NSC lung cancer & Concomitant chemo-radiation \\
\hline Sulfasalazine & 500 mg bid & Oral & GIM-enteropathy & Prevention & Unmentioned & Pelvic radiation \\
\hline Octreotide & $>100 \mathrm{~g}$ & SO & GIM-diarrhea & Treatment & $\mathrm{HSCT}$ & Std/high dose chemotherapy \\
\hline Probiotics & Unmentioned & Oral & GIM-diarrhea & Prevention & Pelvic malignancy & Chemo-radiation therapy \\
\hline Amifostine & $>340 \mathrm{mg} / \mathrm{m}^{2}$ & IV & GIM-radiation proctitis & Prevention & Unmentioned & Receiving radiation therapy \\
\hline Sucralfate & Unmentioned & Enema & GIM-chronic radiation proctitis & Treatment & Unmentioned & Patients with rectal bleeding \\
\hline Hyperbaric 02 & Unmentioned & - & Radiation-induced proctitis & Treatment & Solid tumor & Radiation for solid tumor \\
\hline \multicolumn{7}{|c|}{ Oral mucositis (stomatitis) } \\
\hline Cryotherapy & 30 min prior & Oral & Oral mucositis & Prevention & Unmentioned & Receiving bolus 5-fluorouracil \\
\hline Cryotherapy & Unmentioned & Oral & Oral mucositis & Prevention & $\mathrm{HSCT}$ & $\begin{array}{l}\text { High dose melphalan } \pm \text { total } \\
\text { body radiation }\end{array}$ \\
\hline LLLT & $650.0 \mathrm{~nm}$ & Oral & Oral mucositis & Prevention & $\mathrm{HSCT}$ & $\begin{array}{l}\text { High dose chemo } \pm \text { total } \\
\text { body radiation }\end{array}$ \\
\hline LLLT & $632.8 \mathrm{~nm}$ & Oral & Oral mucositis & Prevention & HNC & Radiation \pm chemo \\
\hline Palifermin & Protocol & IV & Oral mucositis & Prevention & $\mathrm{HSCT}$ & $\begin{array}{l}\text { High dose chemo plus } \\
\text { total body radiation }\end{array}$ \\
\hline Benzydamine & $0.5 \%$ & Oral Rinse & Oral mucositis & Prevention & HNC & $\begin{array}{l}\text { Mod radiation < } 50 \text { Gy } \\
\text { Without chemotherapy }\end{array}$ \\
\hline Zinc & Unmentioned & Oral & Oral mucositis & Prevention & Oral cancer & Radiation or chemotherapy \\
\hline Oral Hygiene & Unmentioned & Oral & Oral mucositis & Prevention & All cancers & $\begin{array}{l}\text { All treatment modalities in } \\
\text { all age groups }\end{array}$ \\
\hline \multicolumn{7}{|l|}{ Pain attenuation } \\
\hline Morphine & Unmentioned & IV & Mucositis pain & Treatment & HSCT & $\begin{array}{l}\text { High dose chemo } \pm \text { total } \\
\text { body radiation }\end{array}$ \\
\hline Fentanyl & Unmentioned & Transdermal & Mucositis pain & Treatment & Unmentioned & $\begin{array}{l}\text { High dose chemo } \pm \text { total } \\
\text { body radiation }\end{array}$ \\
\hline Morphine & $2 \%$ solution & Oral rinse & Mucositis pain & Treatment & $\mathrm{HNC}$ & Chemo-radiation \\
\hline Doxepin & $0.5 \%$ solution & Oral rinse & Mucositis pain & Treatment & Unmentioned & Unmentioned \\
\hline
\end{tabular}

MASCC, multinational Association of Supportive Cancer Care; IV, intravenous; GIM, gastrointestinal mucositis; NSC, non-small cell; SQ, subcutaneous; HSCT, human stem cell transplant; Std, standard; LLLT, low level laser therapy; HNC, head and neck cancer. 
five different interventions. Counterbalancing these supportive positions for the management of OM, there are five MASCC recommendations against the use of four different interventions and five suggestions against the use of five different interventions intended to either treat or prevent OM varying cancer treatment scenarios. For the management of gastrointestinal mucositis (GIM which includes the esophagus) there are two 'recommendations' and five 'suggestions' favoring the use of seven different interventions to manage gastrointestinal mucositis (GIM) with four interventions supported for prevention of GIM and three for the treatment of GIM. There are three recommendations against the use of other interventions for GIM.

Of the guidelines for seven interventions to manage OM, none are for treatment or reversal. Of the seven interventions recommended or suggested "to prevent' OM, each lowers but does not completely eliminate the incidence of severe grades of OM (grades $3,4)$. None of the seven can prevent or reduced the incidence moderate grades of OM (grades 1,2) which leads to dose reduction, thereby lower survival, with chemoradiotherapy [13] more frequently than Grade 3,4 (23\% vs. 21\%). Guidelines support the use of standard potency non-polymerized non-cross-linked generic sucralfate as an enema for the treatment of chronic radiation-induced proctitis in patients with rectal bleeding. However, the use of generic sucralfate is recommended against for the treatment of GIM, for the prevention and treatment of OM. High potency polymerized cross-linked sucralfate has yet to be reviewed by MASCC/ISOO.

\section{Statistically better than placebo but short of clinical expectation}

The magnitude of treatment effect for each intervention cited by MASCC guidelines are statistically better than placebo, but only incrementally so [47]. Their effect on mucositis is fractional. No intervention, singly or in combination [49] satisfactorily meet the clinical expectation of substantial mitigation or complete and sustained elimination of mucositis. The incidence and persistence of mucositis throughout the entire length of GI tract is largely unchallenged by these interventions during chemo-radiation treatment. Therefore, the fractional improvements over placebo provided by these interventions, though statistically significant, are inadequate to negate mucositis-associated consequences of chemo-radiation. Additionally, the manner of presentation of interventions in the MASCC guidelines, imply that - differing causes of mucositis (radiation versus targeted immunotherapies and non-targeted cytotoxic agents) occurring at different anatomical locations in the GI tract under specific scenarios of cancer treatment—will likely require different anti-mucositis interventions.
This concept was not supported by the treatment outcomes reported herein for HPPCLS, wherein mucositis arising in various scenarios responded similarly and completely without regard to cause of mucositis or the antatomical location of its occurrence.

\section{Anti-mucositis agents in Korea}

Intravenous palifermin, human keratinocyte growth hormone, FDA approved in 2004 in the US, was granted orphan status in Korea in 2011, wherein phase 3 trials sponsored by the Catholic University of Korea (NCT02313792) and registered in 2014. It has yet to be cleared for marketing in Korea, being available on a named -patient basis. A recent study of the use of palifermin raised doubt as to overall benefit when palifermin was substituted for intensive oral care in combination with several MASCC and non-MASCC interventions showed no different in overall mucositis outcomes [49]; 75\% of all patients in each group fail to respond to interventions with or without palifermin. Furthermore, recently published pharmacoeconomic analysis of palifermin over period of 2002 to 2010 found that while associated with increased cost of 5-14,000 dollars per case of autologous hematopoietic stem cell transplant (HSCT) it did not provide a cost-effective approach for the elimination of mucositis [55].

The approval of oral recombinant human epithelial growth factor in Korea in 2011 have not found widespread usefulness in oncology as it cannot prevent mucositis, nor can it rapidly reverse radiation-induced oral mucositis despite early promising reports [56]. At present rhEGF spray in Korea is more widely used to manage diabetic skin ulcers.

FDA approved oral rinses with similar effects in lessening the discomfort of mucositis but do not address the process of mucositis directly [57]. Glycerin carbomer homopolymer A (MuGard) was FDA approved for oral mucositis in the US in 2006, followed by market approval in Korea in 2015. Though marketed for the management of oral mucositis, the conclusion of recently published research in 2014 on 37 patients receiving placebo and 41 patients using MuGard, was that "Despite MuGard's efficacy in attenuating mouth throat soreness, it was not superior to controls in impacting subjects' ability to swallow, eat, or drink. Nor did $\mathrm{MuGard}$ significantly alter gastrostomy reliance, unplanned office visits, emergency room visits, or hospitalizations" [58]. Despite their differences in composition similar outcomes have been reported for other FDA approved oral rinses (Gelclair, Caphosol, Episil).

\section{Elimination of cancer treatment toxicities}

Over the past 40 years, to optimize dose intensity of cancer treatments and minimize unplanned treatment breaks, chemoradia- 
tion-induced toxicities have been targeted for complete elimination or at least substantial minimization. These toxicities included mucositis, anemia, neutropenia, immediate and delayed onset of nausea and vomiting and diarrhea. While therapeutic interventions for treatment-induced anemia, neutropenia and immediate (and delayed)-onset nausea and vomiting have be successful, interventions approved or recommended for mucositis have not met meaningful clinical expectations. Still $75 \%$ to $80 \%$ of patients with treatment-induced mucositis remain substantively unresponsive to the interventions of the MASCC guidelines, to FDA approved recombinant keratinocyte growth factor (palifermin), to KFDA approved human epithelial growth factor or FDA and KFDA registered oral rinses.

The annual prospect of mucositis-associated premature deaths due to both unplanned treatment breaks and mucositis-mediated infections is certain for approximately 5,214 patients in Korea and 42,501 patients in US, over $18 \%$ of all mucositis patients. For them, only complete elimination or substantial minimization of mucositis would remove unplanned breaks in therapy and mucositis-mediated infections.

Treatment-induced mucositis is a medical emergency, toxicity to be eliminated rather than a complication to be accepted and tolerated. It is a main driver of unplanned breaks in treatment, simultaneously contributing to severe physical debilitation, suffering and the increased immediate costs of care.

Clinical adherence to a prescribed schedule of treatments optimizes the dose-intensity required to achieve satisfactory therapeutic outcomes. Unplanned treatment interruptions dilute dose intensity necessary to counter the treatment-accelerated tumor repopulation $[23,34,59]$ with its associated reductions in periods of disease free-states and overall 5 year survival [27-29].

For the 55 patients reported here, the single agent protocol (Table 2), using HPPCLS for complete mucositis prevention or rapid reversal removed eliminated the risk of unplanned breaks and thereby the consequences of lowered dose-intensity during cancer treatment. Additionally, for these 55 patients, HPPCLS eliminated immediate morbidity and suffering from poorly managed mucositis with its associated increased costs of care due to dehydration, emergency room visits and hospitalization.

The value of complete elimination or extensive minimization of mucositis during cancer treatment is substantial, particularly given the number of patients in Korea and in the US, annually at risk for these mucositis-associated consequences.

\section{CONFLICT OF INTEREST}

Author is an employee of the company that markets the US prod- uct containing HPPCLS (ProThelial).

\section{REFERENCES}

1. Medicare Managed Care Manual: Chapter 4. Benefits and Beneficiary Protections [Internet]. Baltimorel: U.S. Centers for Medicare \& Medicaid Services; [cited 2016 Apr 22]; [29-30 p.]. Available from: https://www.cms.gov/Regulations-and-Guidance/Guidance/Manuals/downloads/mc86c04.pdf.

2. Gratwohl A, Brand R, Frassoni F, Rocha V, Niederwieser D, Reusser $\mathrm{P}$, et al. Cause of death after allogeneic haematopoietic stem cell transplantation (HSCT) in early leukaemias: an EBMT analysis of lethal infectious complications and changes over calendar time. Bone Marrow Transplant 2005;36:757-69.

3. Alden ME, O'Reilly RC, Topham A, Lowry LD, Brodovsky H, Curran WJ Jr. Elapsed radiation therapy treatment time as a predictor of survival in patients with advanced head and neck cancer who receive chemotherapy and radiation therapy. Radiology 1996;201:675-80.

4. Herrmann T, Jakubek A, Trott KR. The importance of the timing of a gap in radiotherapy of squamous cell carcinomas of the head and neck. Strahlenther Onkol 1994;170:545-9.

5. Park Y, Kim YH. Chemotherapy related oral and gastrointestinal mucositis. J Korean Med Assoc 2009;52:897-906.

6. Jo KS, Kim NC. Incidence and factors influencing oral mucositis in patients with hematopoietic stem cell transplantation. J Korean Acad Nurs 2014;44:542-51.

7. Cho HK, Jeong YM, Lee HS, Lee YJ, Hwang SH. Effects of honey on oral mucositis in patients with head and neck cancer: A metaanalysis. Laryngoscope 2015;125:2085-92.

8. NCCN Oncology Guidelines [Internet]. Washington: National Comprehensive Cancer Network; 2016 [cited 2016 Dec 25]. Available from: https://www.nccn.org/professionals/physician_gls/f_ guidelines.asp\#site.

9. Kolodziej M, Hoverman JR, Garey JS, Espirito J, Sheth S, Ginsburg A, et al. Benchmarks for value in cancer care: an analysis of a large commercial population. J Oncol Pract 2011;7:301-6.

10. Jung KW, Won YJ, Kong HJ, Oh CM, Cho H, Lee DH, et al. Cancer statistics in Korea: incidence, mortality, survival, and prevalence in 2012. Cancer Res Treat 2015;47:127-41.

11. Jung KW, Park S, Kong HJ, Won YJ, Boo YK, Shin HR, et al. Cancer statistics in Korea: incidence, mortality and survival in 2006-2007. J Korean Med Sci 2010;25:1113-21.

12. Lee JW, Kim CC. The activity of hematopoietic stem cell transplantation in Korea. Bone Marrow Transplant 2008;42:S92-5.

13. Elting LS, Cooksley C, Chambers M, Cantor SB, Manzullo E, Rubenstein EB. The burdens of cancer therapy. Clinical and eco- 
nomic outcomes of chemotherapy-induced mucositis. Cancer 2003;98:1531-9.

14. Murphy BA. Clinical and economic consequences of mucositis induced by chemotherapy and/or radiation therapy. J Support Oncol 2007;5:13-21.

15. Trotti A, Bellm LA, Epstein JB, Frame D, Fuchs HJ, Gwede CK, et al. Mucositis incidence, severity and associated outcomes in patients with head and neck cancer receiving radiotherapy with or without chemotherapy: a systematic literature review. Radiother Oncol 2003;66:253-62.

16. Elting LS, Keefe DM, Sonis ST, Garden AS, Spijkervet FK, Barasch A, et al. Patient-reported measurements of oral mucositis in head and neck cancer patients treated with radiotherapy with or without chemotherapy: demonstration of increased frequency, severity, resistance to palliation, and impact on quality of life. Cancer 2008; 113:2704-13.

17. Elting LS, Cooksley CD, Chambers MS, Garden AS. Risk, outcomes, and costs of radiation-induced oral mucositis among patients with head-and-neck malignancies. Int J Radiat Oncol Biol Phys 2007;68:1110-20.

18. Stiff PJ, Emmanouilides C, Bensinger WI, Gentile T, Blazar B, Shea TC, et al. Palifermin reduces patient-reported mouth and throat soreness and improves patient functioning in the hematopoietic stem-cell transplantation setting. J Clin Oncol 2006;24:5186-93.

19. Chaudhry HM, Bruce AJ, Wolf RC, Litzow MR, Hogan WJ, Patnaik MS, et al. The incidence and severity of oral mucositis among allogeneic hematopoietic stem cell transplantation patients: a systematic review. Biol Blood Marrow Transplant 2016;22:60516.

20. Russo G, Haddad R, Posner M, Machtay M. Radiation treatment breaks and ulcerative mucositis in head and neck cancer. Oncologist 2008;13:886-98.

21. Rosenthal DI. Consequences of mucositis-induced treatment breaks and dose reductions on head and neck cancer treatment outcomes. J Support Oncol 2007;5:23-31.

22. Foote M. The importance of planned dose of chemotherapy on time: do we need to change our clinical practice? Oncologist 1998;3:365-8.

23. Tarnawski R, Fowler J, Skladowski K, Swierniak A, Suwinski R, Maciejewski $\mathrm{B}$, et al. How fast is repopulation of tumor cells during the treatment gap? Int J Radiat Oncol Biol Phys 2002;54:229-36.

24. Robertson AG, Robertson C, Perone C, Clarke K, Dewar J, Elia $\mathrm{MH}$, et al. Effect of gap length and position on results of treatment of cancer of the larynx in Scotland by radiotherapy: a linear quadratic analysis. Radiother Oncol 1998;48:165-73.

25. Robertson C, Robertson AG, Hendry JH, Roberts SA, Slevin NJ, Duncan WB, et al. Similar decreases in local tumor control are calculated for treatment protraction and for interruptions in the radiotherapy of carcinoma of the larynx in four centers. Int J Radiat Oncol Biol Phys 1998;40:319-29.

26. Suwinski R, Sowa A, Rutkowski T, Wydmanski J, Tarnawski R, Maciejewski B. Time factor in postoperative radiotherapy: a multivariate locoregional control analysis in 868 patients. Int J Radiat Oncol Biol Phys 2003;56:399-412.

27. Groome PA, O’Sullivan B, Mackillop WJ, Jackson LD, Schulze K, Irish JC, et al. Compromised local control due to treatment interruptions and late treatment breaks in early glottic cancer: population-based outcomes study supporting need for intensified treatment schedules. Int J Radiat Oncol Biol Phys 2006;64:1002-12.

28. Barton MB, Keane TJ, Gadalla T, Maki E. The effect of treatment time and treatment interruption on tumour control following radical radiotherapy of laryngeal cancer. Radiother Oncol 1992; 23:137-43.

29. Fowler JF, Lindstrom MJ. Loss of local control with prolongation in radiotherapy. Int J Radiat Oncol Biol Phys 1992;23:457-67.

30. Withers HR, Peters LJ, Taylor JM, Owen JB, Morrison WH, Schultheiss TE, et al. Local control of carcinoma of the tonsil by radiation therapy: an analysis of patterns of fractionation in nine institutions. Int J Radiat Oncol Biol Phys 1995;33:549-62.

31. Center for International Blood and Marrow Transplant Research (CIBMTR). Health Services Research Program [Internet]. Milwaukee: CIBMTR; 2016 [cited 2016 Dec 26]. Available from: www.cibmtr.org/About/AdminReports/Documents/CIBMTR_ Progress_Report_2014.pdf.

32. Nonzee NJ, Dandade NA, Patel U, Markossian T, Agulnik M, Argiris A, et al. Evaluating the supportive care costs of severe radiochemotherapy-induced mucositis and pharyngitis: results from a Northwestern University Costs of Cancer Program pilot study with head and neck and nonsmall cell lung cancer patients who received care at a county hospital, a Veterans Administration hospital, or a comprehensive cancer care center. Cancer 2008;113:1446-52.

33. Elting LS, Shih YC. The economic burden of supportive care of cancer patients. Support Care Cancer 2004;12:219-26.

34. Schmidt-Ullrich RK, Contessa JN, Dent P, Mikkelsen RB, Valerie K, Reardon DB, et al. Molecular mechanisms of radiation-induced accelerated repopulation. Radiat Oncol Investig 1999;7:321-30.

35. IMS Institute for Healthcare Informatics. Prescriptions for Mucositis in 2012. Parsippany: IMS Institute for Healthcare Informatics; 2013.

36. McCullough RW. Prothelial"' (polymerized cross-linked high potency sucralfate): medical device therapy for treatment and prevention of mucositis. Eur J Med Res 2011;2:30-58.

37. Dodd MJ, Miaskowski C, Greenspan D, MacPhail L, Shih AS, Shiba $\mathrm{G}$, et al. Radiation-induced mucositis: a randomized clinical trial of 
micronized sucralfate versus salt \& soda mouthwashes. Cancer Invest 2003;21:21-33.

38. Franzen L, Henriksson R, Littbrand B, Zackrisson B. Effects of sucralfate on mucositis during and following radiotherapy of malignancies in the head and neck region: a double-blind placebo-controlled study. Acta Oncol 1995;34:219-23.

39. Epstein JB, Wong FL. The efficacy of sucralfate suspension in the prevention of oral mucositis due to radiation therapy. Int J Radiat Oncol Biol Phys 1994;28:693-8.

40. Hollander D, Tarnawski A, Krause WJ, Gergely H. Protective effect of sucralfate against alcohol-induced gastric mucosal injury in the rat: macroscopic, histologic, ultrastructural, and functional time sequence analysis. Gastroenterology 1985;88:366-74.

41. Kashimura K, Ozawa K. Sucralfate Preparations. US Patent 5,968,906. 1999 Oct 19.

42. World Health Organization. WHO handbook for reporting results of cancer treatment. Geneva: World Health Organization; 1979.

43. Cox JD, Stetz J, Pajak TF. Toxicity criteria of the Radiation Therapy Oncology Group (RTOG) and the European Organization for Research and Treatment of Cancer (EORTC). Int J Radiat Oncol Biol Phys 1995;31:1341-6.

44. Glasziou P, Chalmers I, Rawlins M, McCulloch P. When are randomised trials unnecessary? Picking signal from noise. BMJ 2007; 334:349-51.

45. Guyatt GH, Oxman AD, Kunz R, Vist GE, Falck-Ytter Y, Schunemann HJ. What is "quality of evidence" and why is it important to clinicians? BMJ 2008;336:995-8.

46. Oxman AD. Grading quality of evidence and strength of recommendations. Grade of recommendation, assessment, development and evaluation (GRADE) working group. BMJ 2004; 328:1490-4.

47. Howick J, Friedemann C, Tsakok M, Watson R, Tsakok T, Thomas J, et al. Are treatments more effective than placebos? A systematic review and meta-analysis. PLOS One 2013;8:e62599.

48. Spielberger R, Stiff P, Bensinger W, Gentile T, Weisdorf D, Kewalramani T, et al. Palifermin for oral mucositis after intensive therapy for hematologic cancers. N Engl J Med 2004;351:2590-8.

49. Bhatt V, Vendrell N, Nau K, Crumb D, Roy V. Implementation of a standardized protocol for prevention and management of oral mucositis in patients undergoing hematopoietic cell transplantation. J Oncol Pharm Pract 2010;16:195-204.
50. Bensinger W, Schubert M, Ang KK, Brizel D, Brown E, Eilers JG, et al. NCCN Task Force Report. prevention and management of mucositis in cancer care. J Natl Compr Canc Netw 2008;6 Suppl 1:S121.

51. Hensley ML, Hagerty KL, Kewalramani T, Green DM, Meropol N, Wasserman TH, et al. American Society of Clinical Oncology 2008 clinical practice guideline update: use of chemotherapy and radiation therapy protectants. J Clin Oncol 2009;27:127-45.

52. Eilers J HD, Henry K, Johnson LA. Evidence-based interventions for cancer treatment-related mucositis: putting evidence into practice. Clin J Oncol Nurs 2014;18:80-96.

53. Peterson DE, Bensadoun RJ, Roila F. Management of oral and gastrointestinal mucositis: ESMO clinical recommendations. Ann Oncol 2009;20 Suppl 4:174-7.

54. Lalla RV, Bowen J, Barasch A, Elting L, Epstein J, Keefe DM, et al. MASCC/ISOO clinical practice guidelines for the management of mucositis secondary to cancer therapy. Cancer 2014;120:1453-61.

55. Nooka AK, Johnson HR, Kaufman JL, Flowers CR, Langston A, Steuer C, et al. Pharmacoeconomic analysis of palifermin to prevent mucositis among patients undergoing autologous hematopoietic stem cell transplantation. Biol Blood Marrow Transplant 2014;20: 852-7.

56. Hong JP, Lee SW, Song SY, Ahn SD, Shin SS, Choi EK, et al. Recombinant human epidermal growth factor treatment of radiation-induced severe oral mucositis in patients with head and neck malignancies. Eur J Cancer Care (Engl) 2009;18:636-41.

57. Pettit L, Sanghera P, Glaholm J, Hartley A. The use of MuGard"', Caphosol $^{\circ}$ and Episil in patients undergoing chemoradiotherapy for squamous cell carcinoma of the head and neck. J Radiother Pract 2014;13:218-25.

58. Allison RR, Ambrad AA, Arshoun Y, Carmel RJ, Ciuba DF, Feldman E, et al. Multi-institutional, randomized, double-blind, placebo-controlled trial to assess the efficacy of a mucoadhesive hydrogel (MuGard) in mitigating oral mucositis symptoms in patients being treated with chemoradiation therapy for cancers of the head and neck. Cancer 2014;120:1433-40.

59. Withers HR, Taylor JM, Maciejewski B. The hazard of accelerated tumor clonogen repopulation during radiotherapy. Acta Oncol 1988;27:131-46. 